\title{
(6) OPEN ACCESS \\ Congenital heart disease and rheumatic heart disease in Africa: recent advances and current priorities
}

\author{
Liesl Zühlke, ${ }^{1,2}$ Mariana Mirabel, ${ }^{3}$ Eloi Marijon ${ }^{3}$
}

${ }^{1}$ Department of Paediatrics, Red Cross War Memorial Children's Hospital and University of Cape Town, Cape Town, South Africa 2Department of Medicine, Groote Schuur Hospital, Cape Town, South Africa

${ }^{3}$ Paris Cardiovascular Research Centre (PARCC-Inserm U970), European Georges Pompidou Hospital, Paris, France

Correspondence to Dr Liesl Zühlke, Department of Medicine, Groote Schuur Hospital, J46-43 Old Main Building, Observatory 7945, Cape Town, South Africa: liesl.zuhlke@uct.ac.za

Bongani Mayosi is the Guest Editor of this Cardiology in Africa review series.

Received 28 February 2013 Revised 16 April 2013 Accepted 20 April 2013 Published Online First 16 May 2013

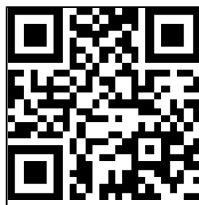

\section{Linked}

- http://dx.doi.org/10.1136/ heartjnl-2013-304130

To cite: Zühlke $L$, Mirabel M, Marijon E. Heart 2013;99:1554-1561.

\begin{abstract}
Africa has one of the highest prevalence of heart diseases in children and young adults, including congenital heart disease (CHD) and rheumatic heart disease (RHD). We present here an extensive review of recent data from the African continent highlighting key studies and information regarding progress in CHD and RHD since 2005. Main findings include evidence that the CHD burden is underestimated mainly due to the poor outcome of African children with CHD. The interest in primary prevention for RHD has been recently reemphasised, and new data are available regarding echocardiographic screening for subclinical RHD and initiation of secondary prevention. There is an urgent need for comprehensive service frameworks to improve access and level of care and services for patients, educational programmes to reinforce the importance of prevention and early diagnosis and a relevant research agenda focusing on the African context.
\end{abstract}

\section{INTRODUCTION}

The epidemiological patterns of heart disease differ greatly between developed nations and sub-Saharan countries, where rheumatic heart disease (RHD) remains a public health issue while congenital heart disease (CHD) bears a poor prognosis. The huge strides made in the developed regions of the world in diagnostic options, and surgical and interventional management of complex CHD have not been replicated in Africa. ${ }^{1}{ }_{2}$ Yet a number of important centres and collaborations have evolved over the past decade in order to address these disparities and renewed attention has been focused on early detection and management of CHD while encouraging innovative approaches and training centres of excellence. ${ }^{1-5}$

In Africa, RHD has demonstrated a particular prevalence in the younger African population. ${ }^{6}$ Since 2006, efforts from affected nations in Africa have resulted in the launch of control and prevention initiatives such as the Drakensberg Declaration and in an invigorated research agenda which has focused attention on echocardiographic screening for RHD leading to the concept of 'subclinical' RHD, and on contemporary trends in management and outcome of patients with tertiary RHD from all over the continent. ${ }^{7-9}$

\section{BURDEN OF CHD IN AFRICA}

The birth prevalence of CHD is thought to be relatively similar the world over, with variations between regions and countries due to genetic, environmental and epigenetic differences. ${ }^{10}$ The estimate of $\sim 8$ per 1000 live births is generally accepted as the most reliable, however a recent systematic review emphasised potential significant differences, with the lowest prevalence rate observed in Africa, particularly among lowest-income populations. ${ }^{11}$ This mainly reflects the paucity of readily available estimates and the urgent need for robust data to support burden of disease calculations in Africa. Given the reductions in under-5 years mortality (albeit less than in developed countries), and coupled with the projected increase in the proportion of African people in the world over the next decades, the number of children and adults affected with CHD in Africa may be vastly underestimated.

Several recent publications have profiled the epidemiology of CHD in children and adults in Africa, emphasising the burden of CHD among patients referred with suspected heart disease. ${ }^{12-14}$ Among children and adults with suspected heart disease the prevalence appears to be dramatically much higher according to recent data from Sudan. ${ }^{15}$ In Cameroon, $13.1 \%$ of patients with suspected cardiac pathologies, aged between 2 months and 41 years (mean age $10 \pm 9$ years), during a 4-year study period, were diagnosed with CHD. ${ }^{16}$ A survey conducted in Mozambique provided an opportunity to assess the prevalence of CHD in the general population of public school children in Maputo. ${ }^{17}$ Five children (out of 2170) had CHD giving a prevalence of 2.3 in 1000 of which $80 \%$ were newly discovered.

Data from northern Nigeria reported that among 1312 patients (aged 9 days to 35 years) with abnormal echocardiograms, $122(9.3 \%)$ had CHD. ${ }^{18}$ The predominant lesions noted were ventricular septal defect and among cyanotic lesions, tetralogy of Fallot. However critical congenital heart defects such as left-sided obstructive lesions were rare, suggesting the poor survival of affected children, and the likelihood that the data available underestimate the true prevalence of CHD.

Children with CHD in Africa have a dramatically different prognosis to those living in developed nations, in terms of morbidity and mortality. ${ }^{1}$ The impact of CHD on admissions for heart failure has been established in southwestern Uganda. ${ }^{19}$ The aetiology of heart failure in this cohort of children $(\mathrm{n}=58)$ was largely due to CHD $(35 \%)$ compared with acquired heart diseases, establishing the importance of CHD as a cause of heart failure among children in Africa. ${ }^{1620}$ A recent review of the profile of CHD in newborns in Bizerte, Tunisia, a middle-income country, revealed that medical 
treatment was indicated in $46.3 \%$ and surgery in $22.5 \%$ of patients with a very high case-fatality rate of $23.8 \%$ over a 9 -year period. $^{21}$ The limited access to surgical programmes means a long waiting list, in particular when the only access to surgery requires sending children abroad for treatment. While early postoperative mortality in children deemed fit for surgery may be as low as $4 \%,{ }^{1}$ the long-term outcome of children sent abroad for surgery is associated with a high mortality rate $(18.8 \%)$ in part related to the delay prior to definitive treatment. ${ }^{22}$ Yet, the majority of congenital cardiac lesions are simple and potentially correctable with suitable medical and surgical facilities. Instead, children living with these lesions in many parts of Africa will die in early teens or adulthood from the long-term effects of cyanosis, pulmonary hypertension and cardiac failure. ${ }^{2}$

\section{BURDEN OF RHD IN AFRICA}

RHD remains the leading cause of acquired heart disease among the young worldwide. ${ }^{23}$ The condition results from repeated acute rheumatic fever (ARF) attacks following exposure to Group A streptococci (GAS) infections. The incidence of ARF has remained particularly challenging to assess accurately and thus, no prospective population-based studies of the incidence of first attack of ARF from Africa is available to date. No reports were included in recent systematic reviews. ${ }^{24} 25$ Incidence may be extrapolated from the median incidence from Middle East and North Africa, estimated to approximately 1314 cases per 100000 and per year. ${ }^{24}$ Even without considering the existence of atypical or asymptomatic forms of GAS autoimmune reaction, these data are probably a gross underestimation of the reality in Africa.

It has been projected that more than 15 million people suffer from RHD worldwide, ${ }^{21}{ }^{24}$ which is likely a significant underestimation according to the increasing data on subclinical RHD. $^{26}$ Historically, sub-Saharan Africa has had the greatest prevalence of clinically detected RHD, ranging from less than 1 to 14 per $1000 .^{8} 23^{27} 28$ It has emerged that previous studies may have markedly underestimated the prevalence of the disease, and recent data suggest that other regions may also present an even higher burden of disease. ${ }^{23} 2930$ Since the first report of echocardiography as a potential screening tool, ${ }^{31}$ surveys were carried out in Mozambique, and subsequently in Uganda and in Senegal. ${ }^{8} 273233$ All these studies demonstrated that echocardiography detects a significant additional number of children with clinically silent RHD, estimated to 7.5-51.6 per 1000 children (figure 1).

It has been calculated that if $1.5 \%$ of people with RHD die each year, the approximate number of deaths due to RHD would range from 233000 to 294000 per year worldwide. ${ }^{24}$ However, the exact mortality rate due to RHD is most probably dramatically underestimated in Africa. A large multinational African study demonstrated that RHD prevails as the most frequent cause of heart failure among children and young adults, and importantly that the 180-day mortality is as high as $17.8 \% .{ }^{34}$ In rural Ethiopia annual mortality rate reaches $12.5 \%$ among patients with RHD. ${ }^{35}$ And as many as $70 \%$ of such patients die under 26 years of age. ${ }^{36}$

The recently published Global Burden of Disease Study reports that the number of years lived with disability due to RHD was estimated in 2010 at 1430 (944-2067) worldwide, a figure that represents up to a fourth of all neoplasms. ${ }^{37}$ Further data are needed to assess the social and economic impact of RHD in sub-Saharan countries. Sensibly, RHD should bear high morbidity due the scarcity of prevention programmes across most sub-Saharan countries, which may strongly impact on social, educational and economic issues. Hospital-based studies recently reported that RHD accounts for $6.6-34.0 \%$ of cardiovascular disease-related hospital admissions or echocardiographic examinations performed in institutions across Africa. ${ }^{16}{ }^{38-42}$ RHD has been documented to be relatively frequent among pregnant women (up to $2.3 \%$ ), although symptomatic forms remains more rarely encountered. ${ }^{43}$ Furthermore, recent data emphasise that pregnancy in patients with RHD remains a challenge bearing high morbidity and mortality, requiring multidisciplinary antenatal and postnatal care. ${ }^{44}$

\section{IMPORTANCE AND CHALLENGES OF EARLY DIAGNOSIS In congenital heart disease}

In Africa, the vast majority of congenital cardiac lesions are not diagnosed prior to birth, due to severely limited antenatal screening for CHD. Early diagnosis of simple lesions can result in timely referral before onset of permanent sequelae yet remains hampered by limited resources. However, recent data reveal improved access to diagnostic services in several parts of Africa. Diagnostic and curative services are being offered in Kenya in the capital cities of Nairobi and Mombasa, while rural communities are being accessed using different models of outreach. ${ }^{45}$ In an integrated clinic in Kisumu, $400 \mathrm{~km}$ west of Nairobi, the most common diagnosis is CHD with the result that early detection and timely referral of CHD is a specific focus of outreach clinics. ${ }^{46}$ Pulse oximetry screening for critical CHD is now recommended in the USA and has been adopted in many parts of the developed world. ${ }^{47}$ While potentially exciting, it is critical that newborn screening in Africa be integrated into existing programmes to identify, manage and treat CHD, rather than creating new vertical programmes.

\section{In rheumatic heart disease}

Although echocardiography may prove a valuable tool in detecting RHD cases at an early stage, fundamental issues remain to be addressed. ${ }^{48-51}$ Echocardiographic detection of morphologically abnormal valves or significant valvular regurgitation does not guarantee later progression to advanced valvular disease, nor has the clinical effectiveness of secondary prophylaxis in this population been proven. A first step towards the assessment of subclinical RHD has been taken through the standardisation of echocardiography criteria under the auspices of the World Heart Federation. ${ }^{26}$ However, if this newly described entity is proven to impact on prognosis, easier ways of detecting the disease may be needed in the field. ${ }^{52}$ Indeed, differences in echo criteria may impact on the case detection rates, making echobased screening particularly challenging. ${ }^{53}$ The ideal screening age is also still unclear. Recent data from Dakar emphasised that adolescents in their late teens should be considered suitable for screening in the light of the higher prevalence of the disease, and the clearer cardiac lesions. ${ }^{33}$ Currently, echo-based screening remains a research tool with several unanswered questions with experts agreeing that antibiotic prophylaxis should be initiated in cases of definite subclinical RHD. ${ }^{5154}$

\section{PRIMARY AND SECONDARY PREVENTION FOR RHD: INTEGRATION INTO SPECIFIC AFRICAN PROGRAMMES}

Prevention for RHD includes: (1) improvement of socioeconomic conditions with better hygiene and housing (i.e. primordial prevention); (2) primary prevention through antibiotic treatment of GAS pharyngitis; and (3) secondary prevention of ARF recurrence by penicillin prophylaxis against repeated or chronic ARF attacks. To date, only South Africa has a national guideline for RHD prevention on the continent (table 1$).^{23} 55$ 


\section{$\square$ Clinical prevalence $\square$ Echo prevalence}

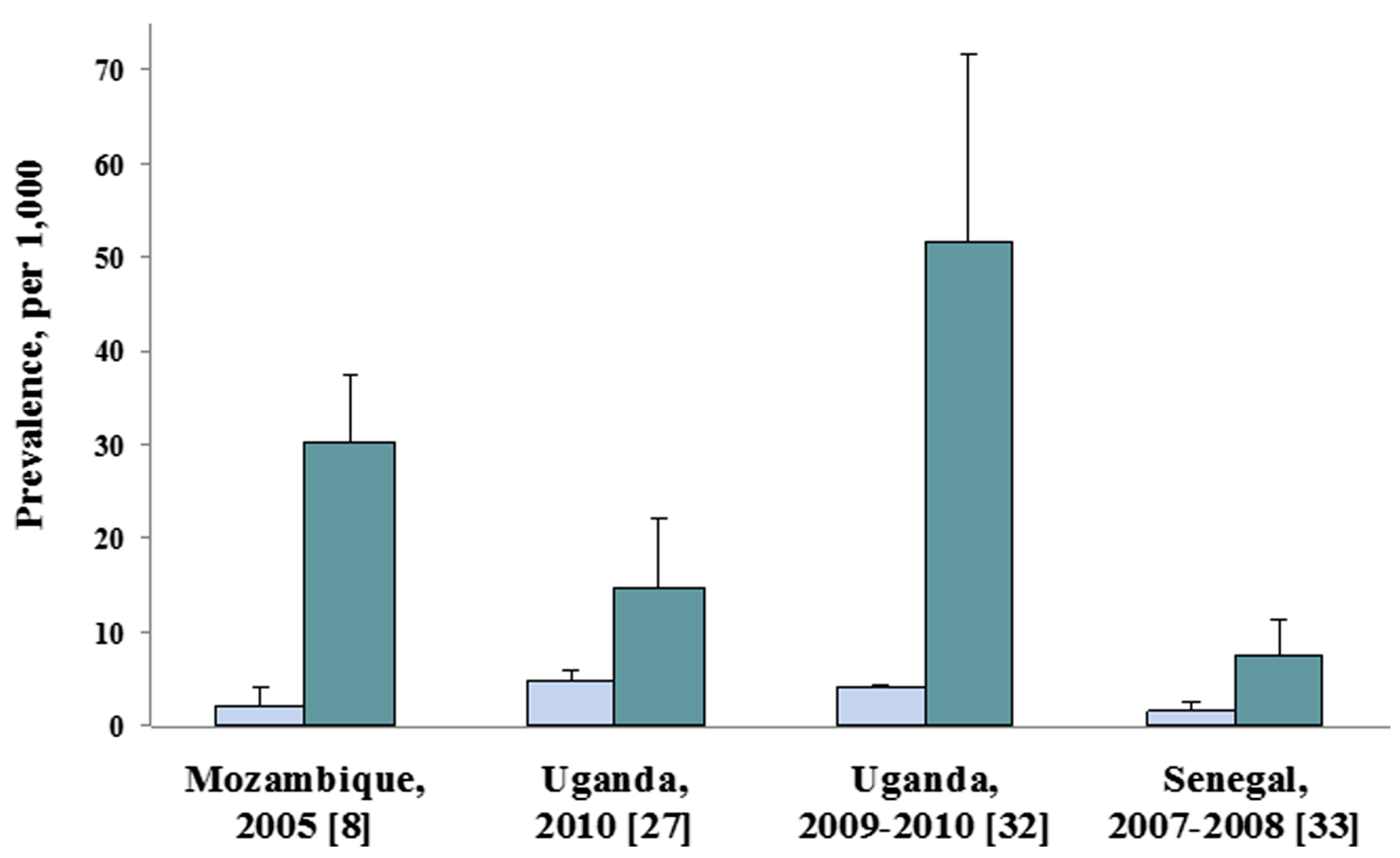

Figure 1 Schoolchildren echo-based screening, Africa 2000-2010. Clinical versus echocardiography (probable and definite lesions) approaches.

Penicillin, a low-cost drug, is the cornerstone to the treatment of RHD since it prevents the advent of ARF and its recurrence. Emphasis should thus be made on the prevention of the disease through comprehensive register-based programmes in order to deliver penicillin for primary and secondary prophylaxis. Safe administration of penicillin is still an issue in many resource-deprived settings and should become a priority in primary care facilities.
To date, primary prevention alone has often been neglected as a large scale strategy in developing countries. ${ }^{59}$ A systematic review on primary prevention showed an overall benefit by preventing $1 \mathrm{ARF}$ case for 53 sore throats treated, ${ }^{60}$ confirmed by the meta-analysis of Lennon et al. ${ }^{61}$ However, these results remain somewhat controversial largely due to the fact that a controlled randomised trial recently failed to demonstrate any

Table 1 Available recommendations for secondary prophylaxis for rheumatic heart disease (RHD)

\begin{tabular}{|c|c|c|c|c|c|c|}
\hline Guidelines & $\begin{array}{l}\text { Preferred } \\
\text { antibiotic }\end{array}$ & $\begin{array}{l}\text { Intramuscular benzathine } \\
\text { benzylpenicillin doses }\end{array}$ & $\begin{array}{l}\text { Interval of } \\
\text { benzathine injections }\end{array}$ & $\begin{array}{l}\text { Oral alternative treatments } \\
\text { and doses }\end{array}$ & Duration & Year \\
\hline $\mathrm{WHO}^{56}$ & $\begin{array}{l}\text { Benzathine } \\
\text { penicillin G }\end{array}$ & $\begin{array}{l}<30 \mathrm{~kg} 600000 \mathrm{U} \\
\geq 30 \mathrm{~kg}: 1200000 \mathrm{U}\end{array}$ & $\begin{array}{l}21 \text { days if high risk } \\
28 \text { days if low risk }\end{array}$ & $\begin{array}{l}\text { Phenoxymethylpenicillin } \\
250 \text { mg twice daily }\end{array}$ & $\begin{array}{l}\text { No evidence of carditis: } 5 \text { years } \\
\text { since last attack or } 18 \text { years* } \\
\text { Resolved carditis: } 10 \text { years since } \\
\text { last attack or } 25 \text { years old* } \\
\text { Moderate -severe or surgery: } \\
\text { Lifelong. }\end{array}$ & 2001 \\
\hline $\begin{array}{l}\text { Australia and } \\
\text { New Zealand }\end{array}$ & $\begin{array}{l}\text { Benzathine } \\
\text { penicillin G }\end{array}$ & $\begin{array}{l}<20 \mathrm{~kg} 600000 \mathrm{U} \\
\geq 20 \mathrm{~kg} 1200000 \mathrm{U}\end{array}$ & $\begin{array}{l}4 \text { weeks ( } 3 \text { weeks for } \\
\text { selected groups) }\end{array}$ & $\begin{array}{l}\text { Phenoxymethylpenicillin } \\
250 \text { mg twice daily }\end{array}$ & $\begin{array}{l}\text { No evidence of carditis: } 10 \text { years } \\
\text { since last attack or } 21 \text { years* } \\
\text { No RHD or mild: } 10 \text { years since } \\
\text { last attack or } 21 \text { years old* } \\
\text { Moderate: until } 35 \text { years Severe: } \\
40 \text { years or longer }\end{array}$ & 2012 \\
\hline India 58 & $\begin{array}{l}\text { Benzathine } \\
\text { penicillin G }\end{array}$ & $\begin{array}{l}<27 \mathrm{~kg} 600000 \mathrm{U} \\
\geq 27 \mathrm{~kg}: 1200000 \mathrm{U}\end{array}$ & $\begin{array}{l}<27 \mathrm{~kg}: 15 \text { days } \\
>27 \mathrm{~kg}: 21 \text { days }\end{array}$ & $\begin{array}{l}\text { Phenoxymethylpenicillin } \\
\text { Children: } 250 \text { mg twice daily } \\
\text { Adults: } 500 \text { mg twice daily }\end{array}$ & $\begin{array}{l}\text { No evidence of carditis: } 5 \text { years } \\
\text { since last attack or } 18 \text { years* } \\
\text { Mild to moderate: } 10 \text { years since } \\
\text { last attack or } 25 \text { years old* } \\
\text { Severe RHD or post-intervention: } \\
\text { Lifelong or until } 40 \text { years of age }\end{array}$ & 2008 \\
\hline South Africa ${ }^{55}$ & $\begin{array}{l}\text { Benzathine } \\
\text { penicillin G }\end{array}$ & $\begin{array}{l}<30 \mathrm{~kg} 600000-900000 \mathrm{U} \\
\geq 30 \mathrm{~kg}: 1200000 \mathrm{U}\end{array}$ & 3 weekly & $\begin{array}{l}\text { Phenoxymethylpenicillin } \\
\geq 30 \mathrm{~kg}: 250 \mathrm{mg} \text { twice daily } \\
<30 \mathrm{~kg}: 125 \mathrm{mg} \text { twice daily }\end{array}$ & $\begin{array}{l}\text { No evidence of carditis: 5years } \\
\text { since last attack or } 18 \text { years* } \\
\text { Established: } 10 \text { years since last } \\
\text { attack or } 25 \text { years old } \\
\text { Severe/post valve replacement: } \\
\text { Lifelong. }\end{array}$ & 1997 \\
\hline
\end{tabular}


benefit of prophylaxis in this setting. ${ }^{62}$ However, by contrast with the previous reports, this last trial refers to a strategy of active ascertainment of pharyngitis in a school system followed by treatment with oral penicillin. Two main arguments have been raised against primary prophylaxis: asymptomatic throat infection, and the possibility of other sites of pathogenic infection (such as skin). ${ }^{63}$ In the African context, there is no available evidence that would favour skin infection in the genesis of ARF. On the other hand, approximately $18 \%$ of schoolchildren are asymptomatic GAS carriers in Ethiopia and may be at risk of developing the classical pharyngitis-ARF pathway. ${ }^{64}$ Experts agree however that primary prophylaxis in developing countries should be based on primary healthcare and cannot rely on the availability of microbiological diagnosis. Clinical scores helping to predict GAS infection had failed in the past, ${ }^{65} 66$ and systematic treatment of sore throat without bacteriological tests have to be advocated in sub-Saharan countries. A better understanding of reasons behind the difficulty of primary prevention has been recently carried out in Tanzania, emphasising the negligence of patients and also medical staff regarding the importance of consulting and treating sore throats. ${ }^{67}$

Vaccine development is the main promise for primary prevention. Most developments have unfortunately targeted strains prevalent in other regions (North America, Europe and Australia), whereas recent African data emphasised the high diversity of GAS emm types among healthy schoolchildren in Ethiopia. ${ }^{68}$ Although research in vaccines using highly conserved antigens and 30-valent $\mathrm{N}$-terminal region remains active, ${ }^{69-71}$ no vaccine is scheduled for phase 2 clinical trials in the foreseeable future. The high heritability and ongoing research on genetic susceptibility may be particularly helpful for a better understanding of the pathogenesis of ARF and may guide vaccine development. ${ }^{72}$

Duration of secondary prophylaxis depends on several factors most important of which is the presence and severity of RHD and the risk of recurrence, suggesting the need for lifelong prophylaxis in the presence of severe RHD or previous heart valve surgery beyond childhood. ${ }^{23}$ Poor compliance has been the principal issue in relatively well-funded programmes. ${ }^{73}$ Compliance with prophylactic benzathine penicillin appears even lower in the African context, being only of $37.5 \%$ after 3 months in Congo. ${ }^{28}$ This particularly low compliance has mainly been reported to be associated with the target population's mobility, understaffing and remote settings.

To the best of our knowledge, there is very scarce data on the cost-effectiveness of prevention in Africa. The principal study evaluated primary prevention-the cost per ARF episode prevented has been estimated at US\$46 in South Africa. ${ }^{60}$ Secondary prophylaxis is thought to be the most cost-effective of interventions, but this has not been verified in any recent African study. Irlam et al have recently assessed the costeffectiveness of primary prophylaxis by a single penicillin injection for pharyngitis in urban South Africa, ${ }^{74}$ and favour the use of a clinical score to guide treatment. ${ }^{75}$ However, these results may not apply to many sub-Saharan countries with markedly lower per capita Gross domestic product than South Africa.

Up to the 2000s, relatively little progress has been made towards achieving the implementation of a comprehensive programme for the secondary prevention of ARF/RHD in Africa. In 2005, African medical practitioners subscribed to the Drakensberg declaration on prevention and control of RHD in Africa. $^{7}$ Known as the Awareness Surveillance Advocacy Prevention project, it calls for a comprehensive strategy based on the pillars of awareness-raising, surveillance, advocacy and prevention to be applied in all African countries. In 2012, the (hospital-based) Rheumatic Heart Disease Global Registry (REMEDY) is the first attempt at comprehensive characterisation of RHD in countries where it is most prevalent. ${ }^{9}$ The aims are to collect detailed data on clinical and echocardiographic features at presentation and follow-up and meticulously document clinical and echocardiographic progression of disease and the occurrence of disease-related adverse events during the course of the study. ${ }^{9}$

\section{INNOVATIONS, ADVANCES AND LOCALLY-APPROPRIATE MANAGEMENT IN SEVERE CHD AND RHD}

Although the percutaneous approach is now the standard approach for definitive correction of defects such as patent ductus arteriosus and valvular pulmonary stenosis, the lack of cardiac catheterisation laboratories has precluded this being introduced into routine clinical practice in many African countries. A recent report from Rwanda however, demonstrated the innovative use of a monoplane conventional C-arm X-ray system and portable ultrasound machine in order to complete several diagnostic and interventional procedures, including closure of atrial septal defects, patent ductus arteriosus and ballooning of valvular pulmonary stenosis. ${ }^{4}$ This has demonstrated the possibility of performing cardiac interventions on children safely and effectively in under-resourced environments with excellent results. Programmes such as these should be strongly encouraged, and expanded to other countries to provide critical services for patients with simple congenital cardiac lesions that can be corrected at a reasonable cost.

The late presentation of CHD presents special challenges, which is unique to the developing country situation, and the need for a structured management pathway. ${ }^{7677}$ It is also apparent from countries with long-established cardiac surgical programmes that increased survival in childhood will lead to an increasing number of patients with grown-up CHD. ${ }^{78}$ In the past decade, there have been major advances in highly technical and expensive catheter interventions for complex CHD such as percutaneous valve replacements, occluders, stents and balloons, and complex hybrid procedures. ${ }^{79}$ These techniques have been successfully introduced to Africa in certain tertiary and quaternary centres. ${ }^{80-83}$ However it is important to note that these interventions are restricted to complex CHD, which is the minority of lesions detected, and to specific centres in South Africa, Egypt and Sudan. These innovations however provide opportunities to develop crucial expertise and serves as an important source of centres of excellence for the whole of Africa. Contextualising interventions in terms of local needs and resources should be integral to the choice of surgery and intervention, especially in view of the vast differences in healthcare funding. Unique African challenges such as malnutrition and poor follow-up initially resulted in a preponderance of palliative procedures, however with review; the benefits of definitive repair are obvious. ${ }^{84}$

Medical and surgical care for people with severe RHD is the least cost-effective intervention and consumes the vast majority of funds available for RHD control in endemic regions. ${ }^{85}$ Sadly, RHD diagnosis in Africa is usually established at an advanced stage of the disease, when severe valve lesions become symptomatic, and significant intervention is indicated. ${ }^{2}$ However, percutaneous mitral dilatation, closed heart mitral commissurotomy and open heart surgery are limited to a few centres in Africa.

Percutaneous mitral balloon commissurotomy has replaced surgical commissurotomy over the past two decades as the 
treatment of choice for significant mitral stenosis and yields excellent outcomes. ${ }^{6}$ It has been recently demonstrated that clinical presentation of mitral stenosis significantly varies across the world with particularly young and severe patients in Africa. ${ }^{86}$ Recent data from Egypt also suggest that redo mitral balloon commissurotomy for mitral restenosis is feasible and safe, and achieves immediate and long-term outcome comparable with initial mitral balloon commissurotomy. ${ }^{87}$

In patients requiring heart surgery, valvuloplasty is always attempted, even at the risk of suboptimal results, owing to its advantages in avoidance of anticoagulation, and thus allowance for pregnancies. Valve replacement presents a dilemma due to the generalised lack of adequate facilities for anticoagulation. Recent experience from Senegal evaluated the mid-term outcome of mitral valve repair in children, demonstrating encouraging results, dependent on careful patient selection and evaluation of lesions. ${ }^{88}$ Findings from South Africa confirm superior long-term outcome in patients who underwent mitral valve repair while also demonstrating reasonable long-term results for mitral valve replacement in an indigent population. ${ }^{89}$

\section{THE AFRICAN HEALTH WORKFORCE CRISIS: A MAJOR BARRIER TO CHD AND RHD MANAGEMENT IN AFRICA}

Sub-Saharan Africa carries over $24 \%$ of the global disease burden but is home to only $3 \%$ of the global health workforce, in sharp contrast to the Americas, with only $10 \%$ of the world disease burden but $37 \%$ of the global health workforce. ${ }^{90}$ It has been said that this inequity in the global health workforce represents the greatest impediment to health in sub-Saharan Africa. Ethiopia has one of the lowest doctors to population ratio with only 1600 doctors serving a population of 83 million and like other countries in Africa, has been plagued by high attrition rates of qualified staff and significant migration of health professionals, including pharmacists, nurses and laboratory technicians, to developed nations or local private organisations. ${ }^{91}$ The response from the Ethiopian health ministry in 2008 was a commitment to increase the number of practising doctors in the country by 9000 over the following 4 years. ${ }^{92}$ Incentives have

Table 2 Crucial areas of further research, clinical practice and critical issues for congenital heart disease (CHD) and rheumatic heart disease (RHD) in Africa

\begin{tabular}{ll}
\hline Research & Epidemiology of CHD \\
& Contemporary burden of disease estimates \\
& Incidence of ARF \\
& Long-term pathogenesis and natural history studies on subclinical \\
& RHD \\
& Ideal age of screening \\
& Cost-effectiveness of echocardiography-based screening \\
Clinical & Antenatal screening of CHD \\
practice & Postnatal screening for CHD: high index of clinical suspicion \\
& Postnatal screening for critical CHD \\
& Essential medicines, for example, penicillin, heart failure \\
& medicines and point-of-care INR \\
Critical & Advocacy around cardiovascular diseases, congenital and \\
issues & acquired. \\
& Funding: innovative methods of funding of programmes for \\
& prevention, diagnosis and management \\
& Training for community, healthcare workers and patients with \\
& RHD and CHD \\
& Awareness raising for CHD and RHD \\
& Health worker retention and incentives \\
& Development of integrated management pathways \\
& Strengthening of health systems including primary healthcare \\
\hline ARF, Acute Rheumatic Fever. INR, International Normalized Ratio.
\end{tabular}

been introduced for doctors alongside a targeted programme to improve primary healthcare resulting in a vast increase in the number of primary health workers. Similar country-led and country-specific interventions that seek solutions beyond the health sector are urgently required throughout the continent. The most pressing needs and urgent research priorities for RHD and CHD are summarised in table 2.

The need for sufficient health workers to be trained, sustained and retained in sub-Saharan African countries cannot be overemphasised.

\section{CARDIAC SURGERY IN AFRICA: ROLE OF CONTINENTAL (NORTH-SOUTH) AS WELL AS SOUTH-SOUTH COLLABORATIONS}

Efforts to overcome the multiple barriers to cardiac surgery have resulted in humanitarian projects along two patterns: (1) transfer of children to receive cardiac surgical care abroad, either pro bono or at reduced fees or (2) visiting surgical teams. Both of these models have demonstrated successes; ${ }^{88}$ however these are not tenable long-term solutions. We now see a paradigm shift in terms of cooperation to improve access to cardiac surgery for congenital and acquired lesions in Africa.

Several new paediatric cardiac centres are currently funded by non-governmental organisations but run on a permanent basis in African countries. The Salam Centre for cardiac surgery in Sudan, managed by an Italian humanitarian organisation, is the only centre in central Africa offering a free-of-charge service for comprehensive cardiac services. ${ }^{89}$ Another important collaboration is that established in Cameroon. ${ }^{93-96}$ This project has been able to demonstrate its feasibility, while stressing the importance of human resource capacity building and a robust funding mechanism to achieve longevity and long-term sustainability. ${ }^{94}$

The Walter Sisulu Paediatric Centre for Africa in South Africa provided a continental referral centre, training surgeons who would then develop programmes in their own countries. ${ }^{5}$ As a result, the Ghanian National Cardiothoracic Centre (established in 1989), has been accredited by the West African College of Surgeons as a centre of excellence for the training of cardiothoracic surgeons, providing a much needed resource for West Africa, one of the poorest regions in the world. ${ }^{97}$ The Pan African Society of Cardiology is a platform which allows for development of these critical partnerships to serve all the children of Africa: thus far it has helped to establish links between African universities and institutions impacting on training, teaching and outreach. ${ }^{3}$

The final model is that of systematic programme development in order to build a long-term successful programme. Here the focus is on developing and strengthening local teams and the creation of pathways to sustainability. A commitment from all involved parties, including government is paramount. New cardiac programmes such as those established in Mozambique, Namibia and Uganda have adopted the approach of inclusivity and a carefully staged cardiac programme to ensure long-term success. ${ }^{1}$ Figure 2 depicts countries with established cardiac programmes performing at least 100 cases per year, providing training and in some cases, certification for cardiologists or cardiac surgeons. These numbers include surgery for congenital and acquired cardiac lesions in public and private units.

\section{CONCLUSIONS}

Africa continues to carry the heavy burden of RHD in children and young adults while access to appropriate management of CHD, including simple defects, remains to be addressed. New data confirms a high prevalence of subclinical RHD in studies 


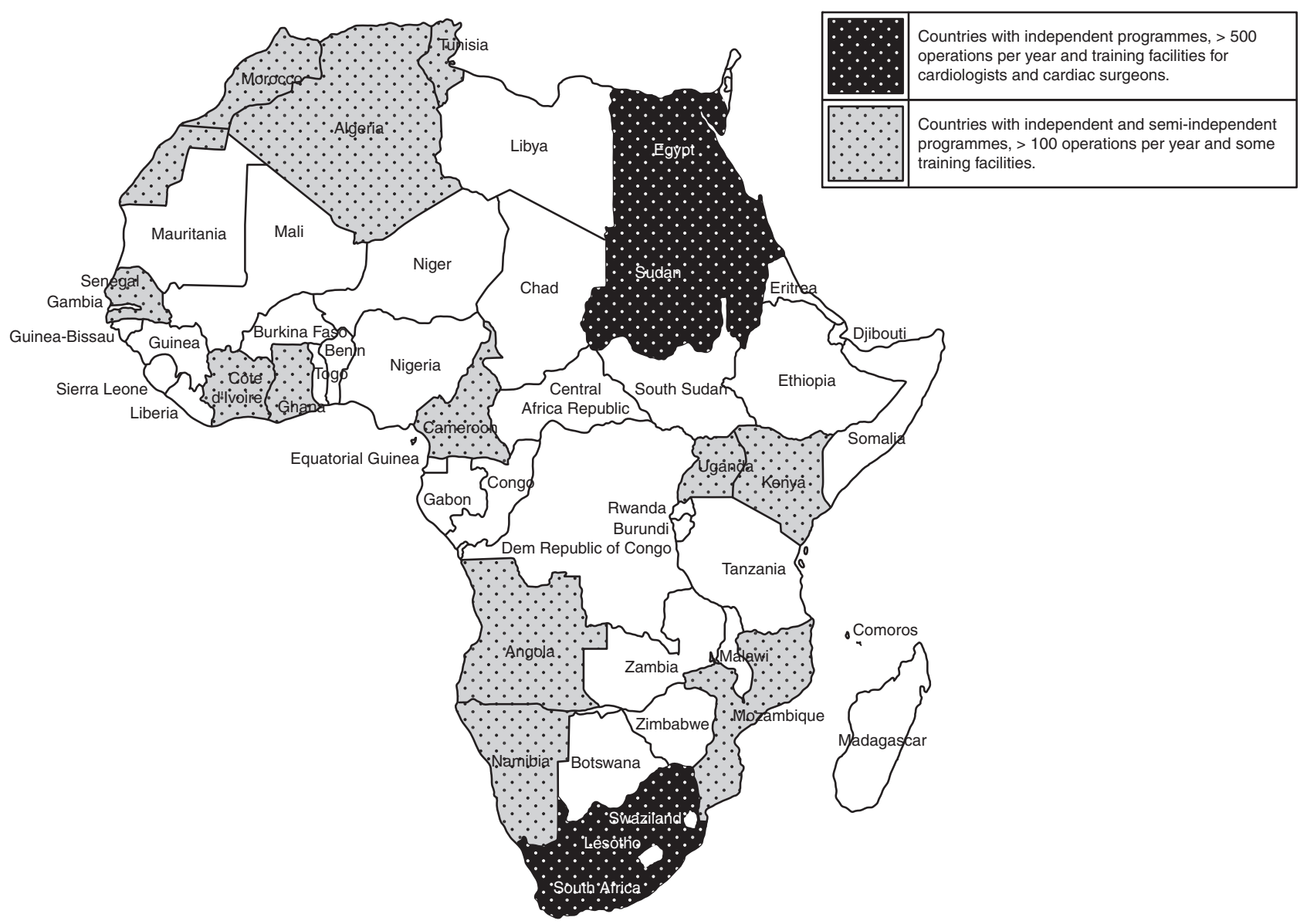

Figure 2 Countries with established cardiac surgery programmes.

from Uganda, Senegal and Mozambique. The application of standardised criteria in follow-up reviews of children with subclinical RHD will be crucial in establishing the role of early echo-based detection of RHD. Primary prophylaxis of ARF may be a cost-effective prevention strategy in middle-income African countries. Although comprehensive prevention programmes (focused on early detection and treatment of RHD and CHD) are still lacking in most African countries, several critical partnerships have been established in the recent decade to facilitate improved management of those with congenital and acquired heart disease. Most importantly multisectoral and multidisciplinary platforms have given rise to new cardiac centres acting as continental centres of excellence, comprehensive integrated service frameworks and landmark research focusing on the African context.

Contributors $L Z$ and EM prepared the first draft and edited all subsequent drafts. MM provided critical review of the first draft and then edited all subsequent drafts. EM prepared figure 1 and table 1 and LZ table 2 and figure 2. All authors contributed to the final submission and approved the final version.

Funding $L Z$ is funded by the Thrasher Foundation, Clinical Infectious Diseases Research Initiative, University of Cape Town Medical Research Council of South Africa and the Hamilton Naki Clinical Scholarship Programme funded by Netcare Limited.

\section{Competing interests None.}

Provenance and peer review Commissioned; externally peer reviewed.

Open Access This is an Open Access article distributed in accordance with the Creative Commons Attribution Non Commercial (CC BY-NC 3.0) license, which permits others to distribute, remix, adapt, build upon this work non-commercially, and license their derivative works on different terms, provided the original work is properly cited and the use is non-commercial. See: http://creativecommons.org/ licenses/by-nc/3.0/

\section{REFERENCES}

1 Mocumbi AO, Lameira $E$, Yaksh $A$, et al. Challenges on the management of congenital heart disease in developing countries. Int J Cardiol 2011;148:285-8.

2 Mocumbi AO. The challenges of cardiac surgery for African children. Cardiovasc J Afr 2012:23:165-7.

3 Watkins DA, Omokhodion SI, Mayosi BM. The history of the Pan-African Society of Cardiology (PASCAR): the first 30 years, 1981-2011. Cardiovasc J Afr 2011;22:122-3.

4 Senga J, Rusingiza E, Mucumbitsi J, et al. Catheter interventions in congenital heart disease without regular catheterization laboratory equipment: the chain of hope experience in rwanda. Pediatr Cardiol 2013;34:39-45.

5 Buchanan E. Walter Sisulu Paediatric Cardiac Centre opened by Nelson Mandela. S Afr Med Je 2004:94:14.

6 Essop MR, Nkomo VT. Rheumatic and nonrheumatic valvular heart disease: epidemiology, management, and prevention in Africa. Circulation 2005;112:3584-91.

7 Mayosi B, Robertson K, Volmink J, et al. The Drakensberg declaration on the control of rheumatic fever and rheumatic heart disease in Africa. So Afr Med $\rfloor$ 2006;96(3 Pt 2):246.

8 Marijon $\mathrm{E}, \mathrm{Ou}$, Celermajer DS, et al. Prevalence of rheumatic heart disease detected by echocardiographic screening. N Engl I Med 2007;357:470-6.

9 Karthikeyan G, Zuhlke L, Engel M, et al. Rationale and design of a Global Rheumatic Heart Disease Registry: the REMEDY study. Am Heart $J$ 2012;163:535-40 e1.

10 Hoffman Jl, Kaplan S. The incidence of congenital heart disease. J Am Coll Cardiol 2002;39:1890-900.

11 van der Linde $D$, Konings EE, Slager MA, et al. Birth prevalence of congenital heart disease worldwide: a systematic review and meta-analysis. J Am Coll Cardiol 2011:58:2241-7. 
12 George I0, Frank-Briggs Al. Pattern and clinical presentation of congenital heart diseases in Port-Harcourt. Niger J Med 2009;18:211-4.

13 Ali SK. Cardiac abnormalities of Sudanese patients with Down's syndrome and their short-term outcome. Cardiovasc JAfr 2009;20:112-15.

14 Du Toit HJ, Von Oppell UO, Hewitson J, et al. Left ventricular sub-valvar mitral aneurysms. Interact Cardiovasc Thorac Surg 2003;2:547-51.

15 Sulafa KM, Karani Z. Diagnosis, management and outcome of heart disease in Sudanese patients. East Afr Med J 2007;84:434-40.

16 Tantchou Tchoumi JC, Ambassa JC, Kingue S, et al. Occurrence, aetiology and challenges in the management of congestive heart failure in sub-Saharan Africa: experience of the Cardiac Centre in Shisong, Cameroon. Pan Afr Med J 2011:8:11.

17 Marijon E, Tivane A, Voicu S, et al. Prevalence of congenital heart disease in schoolchildren of sub-Saharan Africa, Mozambique. Int J Cardiol 2006;113:440-1.

18 Sani MU, Mukhtar-Yola M, Karaye KM. Spectrum of congenital heart disease in a tropical environment: an echocardiography study. J Natl Med Assoc 2007;99:665-9.

19 Ellis J, Martin R, Wilde P, et al. Echocardiographic, chest X-ray and electrocardiogram findings in children presenting with heart failure to a Ugandan paediatric ward. Trop Doct 2007;37:149-50

20 Omokhodion SI, Lagunju IA. Prognostic indices in childhood heart failure. West Afr J Med 2005;24:325-8.

21 Hammami O, Ben Salem K, Boujemaa Z, et al. Epidemiologic and clinical features of congenital heart diseases in children at the Bizerta Hospital. Tunis Med 2007:85:829-33.

22 Brousse $V$, Imbert $P$, Mbaye $P$, et al. Evaluation of long-term outcome of Senegalese children sent abroad for cardiac surgery. Med Trop (Mars) 2003:63:506-12.

23 Marijon E, Mirabel M, Celermajer DS, et al. Rheumatic heart disease. Lancet 2012;379:953-64.

24 Carapetis JR, McDonald M, Wilson NJ. Acute rheumatic fever. Lancet 2005;366:155-68.

25 Tibazarwa KB, Volmink JA, Mayosi BM. Incidence of acute rheumatic fever in the world: a systematic review of population-based studies. Heart 2008;94:1534-40.

26 Remenyi B, Wilson N, Steer A, et al. World Heart Federation criteria for echocardiographic diagnosis of rheumatic heart disease_-an evidence-based guideline. Nat Rev Cardiol 2012;9:297-309.

27 Beaton A, Okello E, Lwabi P, et al. Echocardiography screening for rheumatic heart disease in Ugandan schoolchildren. Circulation 2012;125:3127-32.

28 Kimbally-Kaky G, Gombet T, Voumbo Y, et al. Rheumatic heart disease in schoolchildren in Brazzaville. Med Trop (Mars) 2008;68:603-5.

29 Omurzakova NA, Yamano Y, Saatova GM, et al. High incidence of rheumatic fever and rheumatic heart disease in the republics of Central Asia. Int J Rheum Dis 2009:12:79-83.

30 Jackson SJ, Steer AC, Campbell H. Systematic review: estimation of global burden of non-suppurative sequelae of upper respiratory tract infection: rheumatic fever and post-streptococcal glomerulonephritis. Trop Med Int Health 2011;16:2-11.

31 Anabwani GM, Bonhoeffer P. Prevalence of heart disease in school children in rura Kenya using colour-flow echocardiography. East Afr Med J 1996;73:215-17.

32 Grimaldi A, Ammirati E, Mirabel $M$, et al. Challenges of using ultrasounds for subclinical rheumatic heart disease screening. Int J Cardiol 2012 [Epub ahead of print].

33 Kane A, Mirabel M, Toure K, et al. Echocardiographic screening for rheumatic heart disease: age matters. Int J Cardiol 2012 [Epub ahead of print].

34 Damasceno A, Mayosi BM, Sani M, et al. The causes, treatment, and outcome of acute heart failure in 1006 Africans from 9 countries: results of the Sub-Saharan Africa survey of heart failure. Arch Intern Med 2012:172:1386-94.

35 Gunther G, Asmera J, Parry E. Death from rheumatic heart disease in rural Ethiopia. Lancet 2006:367:391.

36 Oli K, Asmera J. Rheumatic heart disease in Ethiopia: could it be more malignant? Ethiop Med J 2004;42:1-8.

37 Vos T, Flaxman AD, Naghavi M, et al. Years lived with disability (YLDs) for 1160 sequelae of 289 diseases and injuries 1990-2010: a systematic analysis for the Global Burden of Disease Study 2010. Lancet 2012;380:2163-96.

38 Sani MU, Karaye KM, Borodo MM. Prevalence and pattern of rheumatic heart disease in the Nigerian savannah: an echocardiographic study. Cardiovasc J Afr 2007;18:295-9.

39 Soliman EZ, Juma H. Cardiac disease patterns in northern Malawi: epidemiologic transition perspective. J Epidemio/2008;18:204-8

40 Ansa VO, Ekott JU, Bassey EO. Profile and outcome of cardiovascular admissions at the University of Uyo Teaching Hospital, Uyo-a five year review. Niger J Clin Pract 2008; 11:22-4.

41 Ike SO. Echocardiographic analysis of valvular heart diseases over one decade in Nigeria. Trans R Soc Trop Med Hyg 2008;102:1214-18.

42 Ntusi NB, Mayosi BM. Epidemiology of heart failure in sub-Saharan Africa. Expert Rev Cardiovasc Ther 2009;7:169-80.

43 Otto H, Saether SG, Banteyrga L, et al. High prevalence of subclinical rheumatic heart disease in pregnant women in a developing country: an echocardiographic study. Echocardiography 2011;28:1049-53.
44 Diao M, Kane A, Ndiaye MB, et al. Pregnancy in women with heart disease in sub-Saharan Africa. Arch Cardiovasc Dis 2011;104:370-4.

45 Awori MN, Ogendo SW, Gitome SW, et al. Management pathway for congenital heart disease at Kenyatta National Hospital, Nairobi. East Afr Med J 2007:84:312-17.

46 Yuko-Jowi CA. African experiences of humanitarian cardiovascular medicine: a Kenyan perspective. Cardiovasc Diagn Ther 2012;2:231-9.

47 Thangaratinam S, Brown K, Zamora J, et al. Pulse oximetry screening for critical congenital heart defects in asymptomatic newborn babies: a systematic review and meta-analysis. Lancet 2012:379:2459-64.

48 Marijon E, Ou P, Celermajer DS, et al. Echocardiographic screening for rheumatic heart disease. Bull World Health Organ 2008;86:84.

49 Marijon E, Tafflet $M$, Jouven X. Time to use ultrasound and not stethoscopes for rheumatic heart disease screening. Nat Clin Pract Cardiovasc Med 2008:5:E1-3.

50 Roberts $K$, Colquhoun S, Steer A, et al. Screening for rheumatic heart disease: current approaches and controversies. Nat Rev Cardiol 2013;10:49-58.

51 Zuhlke L, Mayosi BM. Echocardiographic screening for subclinical rheumatic heart disease remains a research tool pending studies of impact on prognosis. Curr Cardiol Rep 2013;15:343.

52 Mirabel M, Celermajer DS, Ferreira B, et al. Screening for rheumatic heart disease: evaluation of a simplified echocardiography-based approach. Eur Heart J Cardiovasc Imaging 2012;13:1024-9.

53 Marijon E, Celermajer DS, Tafflet M, et al. Rheumatic heart disease screening by echocardiography: the inadequacy of World Health Organization criteria for optimizing the diagnosis of subclinical disease. Circulation 2009:120:663-8.

54 Carapetis JR, Zuhlke LJ. Global research priorities in rheumatic fever and rheumatic heart disease. Ann Pediatr Cardiol 2011:4:4-12.

55 Robertson KA, Volmink JA, Mayosi BM. Lack of adherence to the national guidelines on the prevention of rheumatic fever. S Afr Med J 2005;95:52-6.

56 WHO. Rheumatic fever and rheumatic heart disease. Report of a WHO Expert Consultation. Geneva: World Health Organization; 2004.

57 RHD Australia (ARF/RHD writing group). The Australian guideline for prevention diagnosis and management of acute rheumatic fever and rheumatic heart disease. 2nd edn. 2012. http://www.rhdaustralia.org.au/sites/default/files/guideline 0.pdf

58 Saxena A, Kumar RK, Gera RP, et al. Consensus guidelines on pediatric acute rheumatic fever and rheumatic heart disease. Indian Pediatr 2008:45:565-73.

59 Karthikeyan G, Mayosi BM. Is primary prevention of rheumatic fever the missing link in the control of rheumatic heart disease in Africa? Circulation 2009;120:709-13.

60 Robertson KA, Volmink JA, Mayosi BM. Antibiotics for the primary prevention of acute rheumatic fever: a meta-analysis. BMC Cardiovasc Disord 2005;5:11.

61 Lennon D, Kerdemelidis M, Arroll B. Meta-analysis of trials of streptococcal throat treatment programs to prevent rheumatic fever. Pediatr Infect Dis J 2009;28: e259-64.

62 Lennon D, Stewart J, Farrell E, et al. School-based prevention of acute rheumatic fever: a group randomized trial in New Zealand. Pediatr Infect Dis J 2009:28:787-94.

63 McDonald M, Currie BJ, Carapetis JR. Acute rheumatic fever: a chink in the chain that links the heart to the throat? Lancet Infect Dis 2004:4:240-5.

64 Abdissa A, Asrat D, Kronvall G, et al. Throat carriage rate and antimicrobial susceptibility pattern of group A Streptococci (GAS) in healthy Ethiopian school children. Ethiop Med J 2011;49:125-30.

65 Rimoin AW, Walker CL, Chitale RA, et al. Variation in clinical presentation of childhood group A streptococcal pharyngitis in four countries. J Trop Pediatr 2008;54:308-12.

66 Steinhoff MC, Abd el Khalek MK, Khallaf N, et al. Effectiveness of clinical guidelines for the presumptive treatment of streptococcal pharyngitis in Egyptian children. Lancet 1997;350:918-21.

67 Bergmark R, Bergmark B, Blander J, et al. Burden of disease and barriers to the diagnosis and treatment of group a beta-hemolytic streptococcal pharyngitis for the prevention of rheumatic heart disease in Dar Es Salaam, Tanzania. Pediatr Infect Dis J 2010:29:1135-7.

68 Abdissa A, Asrat D, Kronvall G, et al. High diversity of group A streptococcal emm types among healthy schoolchildren in Ethiopia. Clin Infect Dis 2006:42:1362-7.

69 Steer AC, Dale JB, Carapetis JR. Progress toward a global group a streptococcal vaccine. Pediatr Infect Dis J 2013:32:180-2.

70 Steer AC, Law I, Matatolu L, et al. Global emm type distribution of group A streptococci: systematic review and implications for vaccine development. Lancet Infect Dis 2009:9:611-16.

71 Dale JB, Penfound TA, Tamboura B, et al. Potential coverage of a multivalent M protein-based group A streptococcal vaccine. Vaccine 2013;31:1576-81.

72 Engel ME, Stander R, Vogel J, et al. Genetic susceptibility to acute rheumatic fever: a systematic review and meta-analysis of twin studies. PLOS ONE 2011;6:e25326.

73 Eissa $S$, Lee $R$, Binns $P$, et al. Assessment of a register-based rheumatic heart disease secondary prevention program in an Australian Aboriginal community. Aust N Z J Public Health 2005;29:521-5.

74 Irlam JMB, Engel M, Gaziano TA. Primary prevention of acute rheumatic fever and rheumatic heart disease with penicillin in South African children with pharyngitis: a cost-effectiveness analysis.. Circ Cardiovasc Qual Outcomes 2013;in press. 
75 Steinhoff MC, Walker CF, Rimoin AW, et al. A clinical decision rule for management of streptococcal pharyngitis in low-resource settings. Acta Paediatr 2005:94:1038-42.

76 Tchoumi JC, Ambassa JC, Giamberti A, et al. Late surgical treatment of tetralogy of Fallot. Cardiovasc J Afr 2011;22:179-81.

77 Edwin F, Sereboe LA, Tettey MM, et al. Experience from a single centre concerning the surgical spectrum and outcome of adolescents and adults with congenitally malformed hearts in West Africa. Cardiol Young 2010;20:159-64.

78 van der Bom T, Bouma BJ, Meijboom FJ, et al. The prevalence of adult congenital heart disease, results from a systematic review and evidence based calculation. Am Heart J 2012;164:568-75.

79 Crystal MA, Ing FF. Pediatric interventional cardiology: 2009. Curr Opin Pediatr 2010;22:567-72.

80 Brown SC, Boshoff DE, Eyskens B, et al. Use of a microcatheter in a telescopic system to reach difficult targets in complex congenital heart disease. Catheter Cardiovasc Interv 2009;73:676-81.

81 Brown SC, Boshoff DE, Heying R, et al. Stent expansion of stretch Gore-Tex grafts in children with congenital heart lesions. Catheter Cardiovasc Interv 2010; 75:843-8.

82 Takawira FF, Sinyangwe G, Mooloo R. Endovascular covered stent treatment for descending aorta pseudoaneurysm following coarctation of the aorta repair in an infant. Heart Lung Circ 2010;19:745-8.

83 Weich $\mathrm{H}$, Ackermann $\mathrm{C}$, Viljoen $\mathrm{H}$, et al. Transcatheter aortic valve replacement in a patient with an anomalous origin of the right coronary artery. Catheter Cardiovasc Interv 2011;78:1013-16.

84 Brooks A, Geldenhuys A, Zuhlke L, et al. Pulmonary artery banding: still a valuable option in developing countries? Eur J Cardiothorac Surg 2012;41:272-6.

85 Mocumbi AO, Ferreira MB. Neglected cardiovascular diseases in Africa: challenges and opportunities. J Am Coll Cardiol 2010;55:680-7.

86 Marijon $\mathrm{E}$, lung $\mathrm{B}$, Mocumbi $\mathrm{AO}$, et al. What are the differences in presentation of candidates for percutaneous mitral commissurotomy across the world and do they influence the results of the procedure? Arch Cardiovasc Dis 2008;

101:611-17.

87 Rifaie 0, Ismail M, Nammas W. Immediate and long-term outcome of redo percutaneous mitral valvuloplasty: comparison with initial procedure in patients with rheumatic mitral restenosis. J Interv Cardiol 2010;23:1-6.

88 Ciss AG, Diarra 0, Dieng PA, et al. [Mitral valve repair for rheumatic valve disease in children in Senegal: a review of 100 cases]. Med Trop (Mars) 2009;69:278-80.

89 Geldenhuys A, Koshy JJ, Human PA, et al. Rheumatic mitral repair versus replacement in a threshold country: the impact of commissural fusion. $J$ Heart Valve Dis 2012:21:424-32.

90 Anyangwe SC, Mtonga C. Inequities in the global health workforce: the greatest impediment to health in sub-Saharan Africa. Int J Environ Res Public Health 2007;4:93-100

91 Yami A, Hamza L, Hassen A, et al. Job satisfaction and its determinants among health workers in jimma university specialized hospital, southwest ethiopia. Ethiop J Health Sci 2011;21(Suppl 1):19-27.

92 Wasswa $\mathrm{H}$. Ethiopia plans to train extra 9000 doctors to fill gap left by migration. BMJ 2008;336:689.

93 Tchoumi JC Tantchou, Butera G, Giamberti A, et al. Occurrence and pattern of congenital heart diseases in a rural area of sub-Saharan Africa. Cardiovasc J Afr 2011;22:63-6.

94 Tchoumi JC Tantchou, Ambassa JC, Chelo D, et al. Pattern and clinical aspects of congenital heart diseases and their management in Cameroon. Bull Soc Pathol Exot 2011;104:25-8

95 Ngatchou W, Lemogoum D, Menanga AP, et al. [Cardiac surgery in Cameroon. Results at one year of the pilot phase]. Rev Med Brux 2011;32:14-17.

96 Tchoumi JC Tantchou, Butera G. Rheumatic valvulopathies occurence, pattern and follow-up in rural area: the experience of the Shisong Hospital, Cameroon. Bull Soc Pathol Exot 2009;102:155-8.

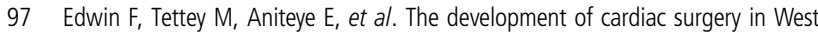
Africa-the case of Ghana. Pan Afr Med J 2011;9:15. 